\title{
Production of a Lipopeptide Biosurfactant by a Novel Bacillus sp. and Its Applicability to Enhanced Oil Recovery
}

\author{
Thivaharan Varadavenkatesan and Vytla Ramachandra Murty \\ Department of Biotechnology, Manipal Institute of Technology, Manipal University, Manipal, Karnataka 576104, India \\ Correspondence should be addressed to Thivaharan Varadavenkatesan; sarasthiva@gmail.com
}

Received 30 April 2013; Accepted 26 August 2013

Academic Editors: G. Benckiser, J. A. Entry, D. Lin, and A. P. Schwab

Copyright ( 2013 T. Varadavenkatesan and V. R. Murty. This is an open access article distributed under the Creative Commons Attribution License, which permits unrestricted use, distribution, and reproduction in any medium, provided the original work is properly cited.

\begin{abstract}
Biosurfactants are surface-active compounds derived from varied microbial sources including bacteria and fungi. They are secreted extracellularly and have a wide range of exciting properties for bioremediation purposes. They also have vast applications in the food and medicine industry. With an objective of isolating microorganisms for enhanced oil recovery (EOR) operations, the study involved screening of organisms from an oil-contaminated site. Morphological, biochemical, and 16S rRNA analysis of the most promising candidate revealed it to be Bacillus siamensis, which has been associated with biosurfactant production, for the first time. Initial fermentation studies using mineral salt medium supplemented with crude oil resulted in a maximum biosurfactant yield of $0.64 \mathrm{~g} / \mathrm{L}$ and reduction of surface tension to $36.1 \mathrm{mN} / \mathrm{m}$ at $96 \mathrm{~h}$. Characterization studies were done using thin layer chromatography and Fourier transform infrared spectroscopy. FTIR spectra indicated the presence of carbonyl groups, alkyl bonds, and C-H and $\mathrm{N}-\mathrm{H}$ stretching vibrations, typical of peptides. The extracted biosurfactant was stable at extreme temperatures, $\mathrm{pH}$, and salinity. Its applicability to EOR was further verified by conducting sand pack column studies that yielded up to $60 \%$ oil recovery.
\end{abstract}

\section{Introduction}

Biosurfactants are amphiphilic molecules which have the ability to depict a wide variety of surface activity. They comprise both a hydrophobic and a hydrophilic group that aid in its accumulation between fluid phases. Biosurfactants have the natural tendency to decrement surface and interfacial tension. Because of this property, they allow easy accessibility to nonpolar hydrocarbons so that microorganisms in oil-rich ecological niches can easily degrade them.

A number of high molecular weight biosurfactants and bioemulsifiers are produced by both bacteria and fungi. Biosurfactants of bacterial origin belong to most classes of compounds including polysaccharides, proteins, lipopolysaccharides, lipoproteins and combinations of many of these structural types. Bacterial strains belonging to the genus Bacillus and Pseudomonas usually produce lipopeptide biosurfactants. Almost all classes of microorganisms (Table 1) produce biosurfactants (Finnerty [1] and Healy et al. [2]).

Owing to their xenobiotic nature, synthetic surfactants have the potential disadvantage of persisting in the environ- ment, long after they are applied for a remedial measure. Also, some of the synthetic surfactants are comparatively more toxic to human health (Dehghan-Noudeh et al. [3]). As biosurfactants are of microbial origin, they have been under the active scrutiny of researchers for more than a decade. Biosurfactants have the potential to be considered as a viable alternative to the chemically synthesized surfactants for environmental cleanup.

According to Habe and Omori [4], the biological treatment of PAH-contaminated soil should be an economically viable and efficient process. The biological approach has a lot of advantages including complete degradation of the pollutants, lower treatment cost, greater safety, and lesser soil disturbance. Kosaric [5] enlisted an exhaustive list of advantages in favour of biosurfactants: biodegradability, low toxicity, biocompatibility and digestibility, availability of raw materials for production, acceptable production economics, environmental control, specificity, and effectiveness. Biodegradation of the hydrocarbons at a specific contaminated site depends on the indigenous soil microbial population, type and concentration of hydrocarbons present, soil characteristics, 
TABLE 1: Examples of microbial biosurfactants.

\begin{tabular}{ll}
\hline Microorganism & Biosurfactant \\
\hline Torulopsis sp. & Sophorolipids \\
Pseudomonas sp. & Rhamnolipids \\
Rhodococcus erythropolis & $\begin{array}{l}\text { Trehalose lipids and mycolates } \\
\text { Sucrose and fructose lipids }\end{array}$ \\
Rhodococcus sp. & Trehalose lipids \\
Candida sp. & Mannosyl erythritol lipid \\
Candida bogoriensis & Sophorolipid \\
Acinetobacter sp. & Fatty acid, glycerides, and emulsan \\
Corynebacterium lepus & Corynemycolic acids \\
Candida petrophilum & Peptidolipid \\
Bacillus subtilis & Cyclic lipopeptide \\
Bacillus licheniformis & Cyclic lipopeptide \\
Candida tropicalis & Mannan-fatty acid complex \\
Corynebacterium & Proteo-lipid-carbohydrate complex \\
hydrocarboclastus &
\end{tabular}

and availability of nutrient and oxygen. The genera of soil microorganisms that are known to degrade hydrocarbons include Pseudomonas, Flavobacterium, Achromobacter, Arthrobacter, Micrococcus, and Acinetobacter (Kosaric [5]). The present work attempts to investigate the use of a novel biosurfactant-producing bacterial strain, isolated from oil-contaminated sites in Manipal (Karnataka, India) for enhanced oil recovery operations.

\section{Materials and Methods}

2.1. Isolation and Enrichment of Microorganisms. Oil-soaked soil samples were collected from a local automobile workshop in Manipal (Karnataka, India). The samples were enriched by inoculating $1 \mathrm{~g}$ of the soil sample into $50 \mathrm{~mL}$ of sterile Bushnell Haas broth (HiMedia, Mumbai) [6], taken in a $250 \mathrm{~mL}$ conical flask at $30^{\circ} \mathrm{C}$ in a shaker incubator (Rotek, India), \& set at $150 \mathrm{rpm}$. The medium was also constituted with filter-sterilized $1 \%(\mathrm{v} / \mathrm{v}) \mathrm{n}$-hexadecane as the sole carbon source. Serial dilution of the sample was performed after $48 \mathrm{~h}$ of incubation and plated onto sterile Bushnell Haas agar plates. After incubation for $48 \mathrm{~h}$ at $30^{\circ} \mathrm{C}$, morphologically distinct colonies were reisolated by transfer to fresh agar plates thrice to obtain pure cultures. The chosen isolates were further screened for the production of biosurfactants using multiple screening methods.

2.2. Screening for Biosurfactant Producers. The preliminary screening assays for biosurfactant production were performed using a variety of methods. 48-hour-old cultures of the isolates grown in Bushnell Haas broth were taken to perform the screening tests. All the screening tests were performed in triplicate.

In the oil spreading technique developed by Morikawa et al. [7], $30 \mathrm{~mL}$ of distilled water was taken in a Petri dish to which $1 \mathrm{~mL}$ of coconut/sesame oil was added to the centre. $20 \mu \mathrm{L}$ of the culture supernatant from the broth was added on top of the oil layer. The Petri dishes were closely observed for a zone of displacement in the oil, and the diameter of displacement was measured.

Blood agar Hemolysis test was performed to check the hemolytic activity of the microbial isolates, as described by Mulligan et al. [8]. The isolates were streaked onto sheep blood agar plates (Himedia, Mumbai) in a sterile environment. The plates were incubated for $48-72$ hours at $30^{\circ} \mathrm{C}$. The bacterial colonies were visually examined for the presence of clear zones around the streaks. The extent of clearing was classified into 4 categories, as described by Rodrigues et al. [9]: no hemolysis; incomplete to partial hemolysis with a clearing $<1 \mathrm{~cm}$; complete hemolysis with a clearing $>1 \mathrm{~cm}$ but $<3 \mathrm{~cm}$; complete hemolysis with a clearing $>3 \mathrm{~cm}$.

The drop collapse test developed by Jain et al. [10] depends on the breakdown of liquid droplets due to surfactant action. Sterile glass slides were coated with commercially available engine oil (SG SAE 20W-40 grade) and fully covered to allow equilibration for 24 hours at room temperature. $0.01 \mathrm{~mL}$ of the culture supernatant was dropped on the surface of the equilibrated glass slides. The shape of the drops was observed for activity of the culture supernatant on the oil after an hour. Depending on the concentration of the crude biosurfactant, the drop collapses to varying degrees. The extent of drop collapse was assessed as follows: no collapse; partial collapse if diameter after collapse $<1 \mathrm{~cm}$; near complete collapse if diameter after collapse $>1 \mathrm{~cm}$ and $<1.5 \mathrm{~cm}$; complete collapse if diameter after collapse $>1.5 \mathrm{~cm}$.

CTAB agar Plate test, developed by Siegmund and Wagner [11], was performed for detection of anionic surfactants. Mineral salts agar (HiMedia, Mumbai) was supplemented with $2 \%(\mathrm{w} / \mathrm{v})$ glucose as carbon source, $0.5 \mathrm{mg} / \mathrm{mL}$ cetyltrimethylammonium bromide (HiMedia, Mumbai), and $0.2 \mathrm{mg} / \mathrm{mL}$ Methylene blue (HiMedia, Mumbai) as performed by Satpute et al. [12]. A well was punctured into the plate using a sterile cork borer and filled with $50 \mu \mathrm{L}$ of the culture supernatant. The plates were incubated for 48-72 hours at $30^{\circ} \mathrm{C}$ and observed for the appearance of bluish/greenish halos around the wells to imply biosurfactant production.

In the tilting glass slide test, developed by Persson and Molin [13], a single colony is picked up from the Bushnell Haas agar plate and transferred on the surface of a sterile glass slide near one of the edges. It is then mixed with a droplet of $1 \%$ saline. The slide is gradually tilted to the other side and was examined for flow of a water droplet over its surface. Biosurfactant production is implied if water flows over the surface.

The surface tension of the 48-hour-old culture broth was measured using a digital surface tensiometer (described in Section 2.7.2). This presents a proportional estimate of the biosurfactant produced by the isolates.

2.3. Bacterial Identification by Biochemical and $16 S$ rRNA Sequencing Technique. The microbial isolate RT10 was identified based on its morphological and biochemical characteristics as per Bergey's Manual of Determinative Bacteriology [14]. Gene sequencing (16S rRNA method) was performed 
at Agharkar Research Institute (Pune, India) to identify the bacterial strain. Genomic DNA was isolated from the culture by using a commercial kit (GenElute Bacterial Genomic DNA Kit, Sigma, USA). A polymerase chain reaction was carried out using the universal primers for $1.5 \mathrm{~kb}$ fragment amplification for eubacteria. The $20 \mu \mathrm{L}$ master mix for the PCR was composed of $3 \mu \mathrm{L}$ of template DNA (10 ng), $2 \mu \mathrm{L}$ each of $200 \mu \mathrm{M}$ dNTP mix and 10X PCR buffer, $0.4 \mu \mathrm{L}$ each of forward and reverse primers, and $0.2 \mu \mathrm{L}$ of Taq DNA polymerase (Bangalore Genei, Bangalore) in $12 \mu \mathrm{L}$ of double distilled water. The PCR was performed using gradient Mastercycler system (Eppendorf, Germany) with the following cycle program: $94^{\circ} \mathrm{C}$ for $5 \mathrm{~min} ; 30$ cycles of $94^{\circ} \mathrm{C}, 60^{\circ} \mathrm{C}$, and $72^{\circ} \mathrm{C}$ for $1 \mathrm{~min}$ each, and final extension at $72^{\circ} \mathrm{C}$ for $10 \mathrm{~min}$ followed by a final sample hold at $4^{\circ} \mathrm{C}$. The PCR product was precipitated using $8.5 \%$ Polyethylene glycol-6000, washed thrice using $70 \%$ ethanol, and dissolved in $10 \mathrm{mM}$ Tris- $\mathrm{HCl}$ $(\mathrm{pH}$ 8). The PCR product was then processed for cycle sequencing reaction. The samples were cleaned up and loaded on the sequencer. The ABI Prism BigDye Terminator Cycle Sequencing Ready Reaction Kit (Applied Biosystems, USA) was used for the sequencing reaction. Samples were run on Avant 3100 Gene Analyzer (Applied Biosystems, USA). The sequencing output was analyzed using the DNA sequence analyzer software (Applied Biosystems). The sequence was compared with National Center for Biotechnology Information (NCBI) GenBank entries by using the BLAST algorithm.

2.4. Screening for Plasmid DNA. Samples of the identified microbial isolate were obtained both from Bushnell Haas Broth and Nutrient Broth (HiMedia, Mumbai). Plasmid extraction was performed using the alkaline lysis method of Birnboim and Doly [15]. Escherichia coli DH5 $\alpha$ cells harbouring the plasmid pUC18 were used as a positive control. The extracted plasmid DNA samples and the control were subjected to agarose gel electrophoresis ( $0.7 \%$ agarose) as described by Sambrouk and Russell [16]. The gel was observed for presence of bands corresponding to plasmid DNA.

2.5. Fermentation Using Crude Oil as Carbon Source. Nutrient broth was used for the preparation of the seed inoculum. The bacterial isolate RT10 was inoculated in $25 \mathrm{~mL}$ sterile nutrient broth in a shaking incubator set at $30^{\circ} \mathrm{C}$ and $150 \mathrm{rpm}$ until $\mathrm{OD}_{600 \mathrm{~nm}}$ reaches 0.8-0.9. This seed culture was used in the production medium at $2 \%(\mathrm{v} / \mathrm{v})$. As formulated by Makkar and Cameotra [17], biosurfactant production was carried out in $250 \mathrm{~mL}$ conical flasks containing $50 \mathrm{~mL}$ of a mineral salt medium with the following composition: $\mathrm{KNO}_{3}(0.3 \%), \mathrm{Na}_{2} \mathrm{HPO}_{4}(0.22 \%), \mathrm{KH}_{2} \mathrm{PO}_{4}(0.014 \%), \mathrm{NaCl}$ (0.001\%), $\mathrm{MgSO}_{4}(0.06 \%), \mathrm{CaCl}_{2}(0.004 \%), \mathrm{FeSO}_{4}(0.002 \%)$, and $0.1 \mathrm{~mL}$ of trace element solution containing $(\mathrm{g} / \mathrm{L})$ : $2.32 \mathrm{~g} \mathrm{ZnSO}_{4} \cdot 7 \mathrm{H}_{2} \mathrm{O}, 1.78 \mathrm{~g} \mathrm{MnSO}_{4} \cdot 4 \mathrm{H}_{2} \mathrm{O}, 0.56 \mathrm{~g} \mathrm{H}_{3} \mathrm{BO}_{3}, 1.0 \mathrm{~g}$ $\mathrm{CuSO}_{4} \cdot 5 \mathrm{H}_{2} \mathrm{O}, 0.39 \mathrm{~g} \mathrm{Na}_{2} \mathrm{MoO}_{4} \cdot 2 \mathrm{H}_{2} \mathrm{O}, 0.42 \mathrm{~g} \mathrm{CoCl}_{2} \cdot 6 \mathrm{H}_{2} \mathrm{O}$, $1.0 \mathrm{~g}$ EDTA, $0.004 \mathrm{~g} \mathrm{NiCl}_{2} \cdot 6 \mathrm{H}_{2} \mathrm{O}$, and $0.66 \mathrm{~g} \mathrm{KI}$ (all chemicals were of analytical grade from Merck, USA). Crude oil (from a local refinery) was used as the sole source of carbon at $2 \%(\mathrm{v} / \mathrm{v})$ concentration. The temperature of the medium was maintained at $30^{\circ} \mathrm{C}$ with shaking at $150 \mathrm{rpm}$. Culture medium samples were drawn for estimation of biomass, biosurfactant production, and surface tension, once every 24 hours for five days. Bacterial cell growth was monitored by measuring the dry cell weight, as described by Cooper and Goldenberg [18] . Biosurfactant concentration in the culture broth was estimated after its crude extraction and concentration. Surface tension was measured with a digital tensiometer. A conical flask without the crude oil was maintained as control. All the experiments were performed in triplicate.

2.6. Extraction of Biosurfactant. The culture broth was centrifuged in a refrigerated centrifuge (Plastocraft Model Superspin $\mathrm{R}-\mathrm{V} / \mathrm{Fm}$, Mumbai) at $10000 \mathrm{rpm}$ for $20 \mathrm{~min}$ at $4^{\circ} \mathrm{C}$ to obtain a cell-free supernatant. The $\mathrm{pH}$ of the supernatant was adjusted to 2 using $6 \mathrm{~N} \mathrm{HCl}$ and was subjected to acid precipitation by placing it at $4^{\circ} \mathrm{C}$ overnight. The off-white precipitate was separated by centrifugation at $10000 \mathrm{rpm}$ for $30 \mathrm{~min}$ at $4^{\circ} \mathrm{C}$. The precipitate was extracted thrice with a 2:1 chloroform-ethanol mixture. The organic phase was removed, and the biosurfactant was concentrated using a rotary evaporator (Superfit Model SuperVac, Mumbai) at $40^{\circ} \mathrm{C}$. The solvents were evaporated leaving behind relatively pure biosurfactant as a viscous light brown matter.

\subsection{Analytical Techniques}

2.7.1. Estimation of Biomass. At periodic time intervals, $1 \mathrm{~mL}$ samples of culture broth were collected in a sterile manner and centrifuged at $10000 \mathrm{rpm}$ for $20 \mathrm{~min}$. The biomass paste was washed thrice with $0.9 \% \mathrm{w} / \mathrm{v}$ saline solution. The paste was dried by heating in a hot air oven set at $50^{\circ} \mathrm{C}-70^{\circ} \mathrm{C}$ until constant weight was attained, without allowing the cells to be charred.

2.7.2. Surface Tension Measurements. The surface tension property was studied by taking a sample of the culture broth and centrifuging at $10000 \mathrm{rpm}$ for $20 \mathrm{~min}$. The cell pellet was discarded, and the surface tension of the supernatant was measured by the Wilhelmy plate method [19] using a Sigma Model 702 digital surface tensiometer (KSV Instruments Ltd., Helsinki, Finland). Initially, the plate and glassware were cleaned with chromic acid, Milli-Q water, and acetone. They were then flamed with a Bunsen burner. The instrument was calibrated beforehand using Milli-Q water. All the measurements were taken in triplicate.

2.7.3. EMI Measurements. The ability of the biosurfactant to emulsify hydrocarbons was determined by the addition of $2 \mathrm{~mL}$ sample of the culture supernatant and $2 \mathrm{~mL}$ of a hydrocarbon (hexadecane), taken in a glass test tube. The tube was vortexed at high speed for $5 \mathrm{~min}$. The emulsification activity was checked after being allowed to settle for $24 \mathrm{~h}$, and the emulsification index $\left(\mathrm{E}_{24}\right)$ was calculated by measuring the emulsion layer, expressed as a percentage of the total height of the mixture in the tube, as described by Cooper and Goldenberg [18]. The emulsification power of a mixture 
of equal volumes of $1 \mathrm{mg} / \mathrm{mL}$ SDS and the hydrocarbon was used as the control.

2.7.4. Thin Layer Chromatography. The biosurfactant sample was spotted on precoated silica gel $60 \mathrm{~F}_{254}$ plate (Merck, USA) and subjected to thin layer chromatography (TLC), as described by Das et al. [20]. The plate was developed with a solvent system consisting of chloroform, methanol, and water $(65: 25: 4)$. The plate was visualized using a short-wave UV lamp. Further, the plate was sprayed with $0.2 \%$ ninhydrin (in absolute alcohol) and heated to $110^{\circ} \mathrm{C}$.

2.7.5. Fourier Transform Infrared Spectroscopy. To understand the overall chemical nature of the extracted biosurfactant, Fourier transform infrared spectroscopy (FTIR) was employed. The technique helps to explore the functional groups and the chemical bonds present in the crude extract. The analysis was done using Shimadzu FTIR Spectrophotometer (Model 8400S). Samples were prepared by homogeneous dispersal of $1 \mathrm{mg}$ of the biosurfactant sample in pellets of potassium bromide (Merck, USA). IR absorption spectra were obtained using a built-in plotter. IR spectra were collected over the range of $450-4500 \mathrm{~cm}^{-1}$ with a resolution of $4 \mathrm{~cm}^{-1}$. The spectral data were the average of 50 scans over the entire range covered by the instrument. The spectrum was studied to interpret the chemical nature of the biosurfactant fraction.

2.8. Stability Analysis of the Biosurfactant. The stability studies were carried out with respect to the effect of temperature, $\mathrm{pH}$, and salinity on surface tension and emulsification capacity of the biosurfactant. The analysis was done using the 24-hour cell-free culture broth obtained by centrifuging the culture sample at $10000 \mathrm{rpm}$ for 15 minutes. All the experiments were carried out in triplicate. To study the effect of temperature, $10 \mathrm{~mL}$ of the cell-free broth was incubated at temperatures ranging from $4^{\circ} \mathrm{C}$ to $121^{\circ} \mathrm{C}$ for 30 minutes. The effect of $\mathrm{pH}$ was determined by estimating the variation of surface activity by adjusting the $\mathrm{pH}$ of $10 \mathrm{~mL}$ of cell-free broth from 2 to 12 with $6 \mathrm{~N} \mathrm{HCl}$ or $6 \mathrm{~N} \mathrm{NaOH}$ solutions. The effect of salinity was checked by varying the concentration of sodium chloride ( $0 \%$ to $20 \% \mathrm{w} / \mathrm{v}$ ), added to $10 \mathrm{~mL}$ samples of cell-free broth. The contents were homogeneously mixed. In all the three studies, the samples were allowed to stand at room temperature for 6 hours after the respective treatments, before making the measurements of surface tension and emulsification index.

2.9. Suitability for Microbial Enhanced Oil Recovery. Microbial enhanced oil recovery (MEOR) is a unique residual oil extraction technology making use of microorganisms. The technique finds great application in enhancing the oil recovery from oil reservoirs. The suitability of the biosurfactant for MEOR was investigated by employing a jacketed glass column as described by Abu-Ruwaida et al. [21]. The performance of the biosurfactant in terms of oil recovery was also compared against sodium dodecyl sulphate (SDS) (Merck, USA), an amphiphilic surfactant and a common ingredient of many commercial detergents. $75 \mathrm{mg}$ of sand was pretreated by washing with $1 \mathrm{~N} \mathrm{HCl}$ in a conical flask, rotated at $150 \mathrm{rpm}$ for 1 hour. It was dried completely in a hot air oven (Rotek, India) set at $100^{\circ} \mathrm{C}$ for 12 hours. A glass column ( $45 \mathrm{~cm} \times 2 \mathrm{~cm}$ i.d.) provided with an external jacket was packed with the sand. The column was saturated with $50 \mathrm{~mL}$ of commercially available engine oil (SL 20W-40; JASO M 345 grade). An aqueous solution of $25 \mathrm{mg}$ biosurfactant in $50 \mathrm{~mL}$ distilled water was applied to the column. The temperature of the column was maintained at $30^{\circ} \mathrm{C}$ by passing water through the jacket using a peristaltic pump coupled to a water bath maintained at $30^{\circ} \mathrm{C}$. The leachate from the column was collected over a 36-hour period, and the volume of engine oil released from the column was measured. The impact of temperature on biosurfactant-mediated oil recovery was observed by conducting similar runs at $50^{\circ} \mathrm{C}$ and $70^{\circ} \mathrm{C}$. In a separate set of studies, an aqueous solution of $25 \mathrm{mg}$ SDS in $50 \mathrm{~mL}$ sterile water was poured onto the column and the oil recovery was determined at $30^{\circ} \mathrm{C}, 50^{\circ} \mathrm{C}$, and $70^{\circ} \mathrm{C}$.

\section{Results and Discussion}

3.1. Isolation and Enrichment of Microorganisms. A total of 11 different bacterial specimens were isolated from the oil contaminated soil samples. The isolates were chosen based on their distinct colony morphology, obtained by serial dilution and streak plating techniques.

3.2. Screening for Biosurfactant Producers. The eleven isolates were then subjected to screening for biosurfactant production by multiple methods like Oil spreading technique, blood agar haemolysis, drop collapse test, CTAB agar plate test, and tilting glass slide test (Table 2).

In the oil spreading technique, Morikawa et al. [7] showed that the extent of oil displacement is directly proportional to the concentration of the biosurfactant produced. Of the eleven isolates, four samples significantly displaced the oil layer and started to spread in the water, showing a zone of displacement. In the blood agar technique, Mulligan et al. [8] relied on the hemolytic activity of the biosurfactant producers. However, it is not necessary that all biosurfactants have a hemolytic activity (Carrillo et al. [22]). Rodrigues et al. [9] scored the hemolytic activity. Accordingly, in the present study, three of the isolates displayed excellent hemolytic activity. Jain et al. [10] described the drop collapse test according to which the degree of collapse of the culture supernatant describes the surfactant concentration. Of the eleven isolates, three strains showed near-complete collapse, while for two other samples the drops turned absolutely flat. In the CTAB test designed by Siegmund and Wagner [11], two isolates showed greenish halos around the colonies on CTAB methylene blue agar medium. The tilted glass slide test, developed by Persson and Molin [13], was positive for four isolates. Water flowed over the slides on which these cultures were tested.

By experiment, none of the isolates showed positive test results for all the six screening procedures. But in the case of RT10, the rate of drop collapse was very rapid and exhibited 
TABLE 2: Summary of the screening tests for biosurfactant producers.

\begin{tabular}{lcccccc}
\hline \multicolumn{7}{c}{ Screening tests } \\
Isolate nos. OST & BAHT & DCT & CTAB & TGST & ST \\
& $(\mathrm{cm})$ & $(\mathrm{cm})$ & $(\mathrm{cm})$ & $($ Green halo $)$ & $(+/-)$ & $(\mathrm{mN} / \mathrm{m})$ \\
\hline RT1 & 2.0 & 2.2 & 0.4 & n.o. & + & 62.3 \\
RT2 & 2.5 & 3.1 & 1.1 & n.o. & - & 39.7 \\
RT3 & 1.3 & 1.8 & 0.2 & Green halo & + & 37.6 \\
RT4 & 2.4 & 2.6 & 1.6 & n.o. & - & 42.6 \\
RT5 & 1.7 & 1.5 & 1.3 & n.o. & - & 59.5 \\
RT6 & 1.0 & 2.5 & 0.5 & n.o. & + & 48.8 \\
RT7 & 2.7 & 3.0 & 1.2 & n.o. & - & 53.2 \\
RT8 & 1.4 & 2.5 & 0.4 & Green halo & + & 42.1 \\
RT9 & 1.7 & 1.9 & 0.0 & n.o. & - & 60.0 \\
RT10 & 3.0 & 3.5 & 1.7 & n.o. & - & 29.8 \\
RT11 & 2.1 & 2.8 & 0.5 & n.o. & - & 64.6 \\
\hline
\end{tabular}

OST: oil spreading technique; BAHT: blood agar Hemolysis test; DCT: drop collapse test;CTAB: CTAB agar plate test; TGST: tilting glass slide test; ST: surface tension; n.o.: not observed; "+": flow observed; "-": flow not observed.

TABLE 3: Morphological features of the bacterial isolate RT10.

\begin{tabular}{lc}
\hline Morphological feature & Observation \\
\hline Shape & Rod \\
Colour & Pale white \\
Size & $2-4$ mm diameter \\
Surface & Shiny \\
Texture & Moist \\
Edge & Entire \\
Elevation & Raised \\
Opacity & Translucent \\
\hline
\end{tabular}

the lowest surface tension of $29.8 \mathrm{mN} / \mathrm{m}$. It satisfied four of the six tests, and hence, this isolate was picked up as a potential candidate for further studies. The current report, henceforth, discusses the potential use of the strain RT10 for enhanced oil recovery.

3.3. Morphological, Biochemical, and $16 S$ rRNA Analysis. The results of screening procedures consistently showed the biosurfactant-producing property of the isolate. The results of almost all the tests led to the selection of the bacterial isolate, RT10. The reduction of surface tension was the greatest in case of RT10. Based on morphological and biochemical analysis, in accordance with Bergey's Manual of Determinative Bacteriology [14], the best isolate belonged to the genus Bacillus (Tables 3 and 4).

The 16S rRNA analysis revealed that the isolate RT10 showed $99.8 \%$ similarity to Bacillus siamensis. The neighborjoining tree based on the $16 \mathrm{~S}$ rRNA sequence for the strain has been shown in Figure 1. The 16S rRNA sequence alignment shows that the strain RT10 was closely related to the species in genus Bacillus.
TABLE 4: Biochemical characteristics of the bacterial isolate RT10.

\begin{tabular}{lc}
\hline Biochemical test & Result \\
\hline Gram staining & Positive \\
Motility test & Motile \\
Starch hydrolysis test & Positive \\
Casein hydrolysis test & Positive \\
Methyl red test & Negative \\
Voges Proskauer test & Positive \\
Citrate utilization test & Negative \\
Catalase test & Positive \\
Glucose fermentation & Positive \\
Endospore staining & Presence of endospore \\
\hline
\end{tabular}

3.4. Screening for Plasmid DNA. The results of the plasmid extraction process did not reveal the presence of any plasmid in the isolate, irrespective of the media in which the cells were cultured. The study infers that the ability of the isolate to produce biosurfactant was not conferred upon due to the presence of any plasmid. The property should be the result of a chromosomally-mediated mechanism of the bacterium.

3.5. Fermentation Using Crude Oil as Carbon Source. Since the isolate was enriched from an oil-contaminated site, preliminary batch fermentation studies were performed in mineral salt medium, Makkar and Cameotra [23], supplemented with $2 \%(\mathrm{v} / \mathrm{v})$ crude oil as the sole carbon substrate. 24-hour cultures were periodically sampled out to monitor the biomass growth, biosurfactant production, and surface tension. As shown in Figure 2, at $96 \mathrm{~h}$ of fermentation maximum biosurfactant yield of $0.64 \mathrm{~g} / \mathrm{L}$, maximum biomass yield of $3.2 \mathrm{~g} / \mathrm{L}$, and the lowest surface tension of $36.1 \mathrm{mN} / \mathrm{m}$ were obtained. The emulsification index $\left(\mathrm{E}_{24}\right)$ of the culture supernatant against hexadecane reached a maximum of $70 \%$ at $72 \mathrm{~h}$.

3.6. Thin Layer Chromatography. When the plate was sprayed with $0.2 \%$ ninhydrin, the biosurfactant component was observed as a single spot on the TLC plate. The observation implied the presence of amino acids in the sample.

3.7. Fourier Transform Infrared Spectroscopy. As a result of $\mathrm{C}-\mathrm{H}$ stretching vibrations and $\mathrm{N}-\mathrm{H}$ stretching vibrations, a broad absorbance peak (centred around $3433 \mathrm{~cm}^{-1}$ ) with wave numbers ranging from $3600 \mathrm{~cm}^{-1}$ to $3100 \mathrm{~cm}^{-1}$ was observed (Figure 3). This is typical of carbon-containing compounds with amino groups. Sharp absorbance peaks are observed at $1463 \mathrm{~cm}^{-1}, 1379 \mathrm{~cm}^{-1}, 2955 \mathrm{~cm}^{-1}$, and $2854 \mathrm{~cm}^{-1}$ and are indicative of aliphatic chains $\left(-\mathrm{CH}_{3}\right.$ and $\left.-\mathrm{CH}_{2}-\right)$. These peaks reflect the presence of alkyl chains in the compound. A strong band was also observed at $1741 \mathrm{~cm}^{-1}$, $1726 \mathrm{~cm}^{-1}$, and $1713 \mathrm{~cm}^{-1}$. This is due to a carbonyl group. The presence of $\mathrm{C}=\mathrm{O}$ bonds causing $\mathrm{C}=\mathrm{O}$ stretching vibrations leads to absorbance peaks in these regions. The FTIR spectrum implied the production of a lipopeptide biosurfactant. 


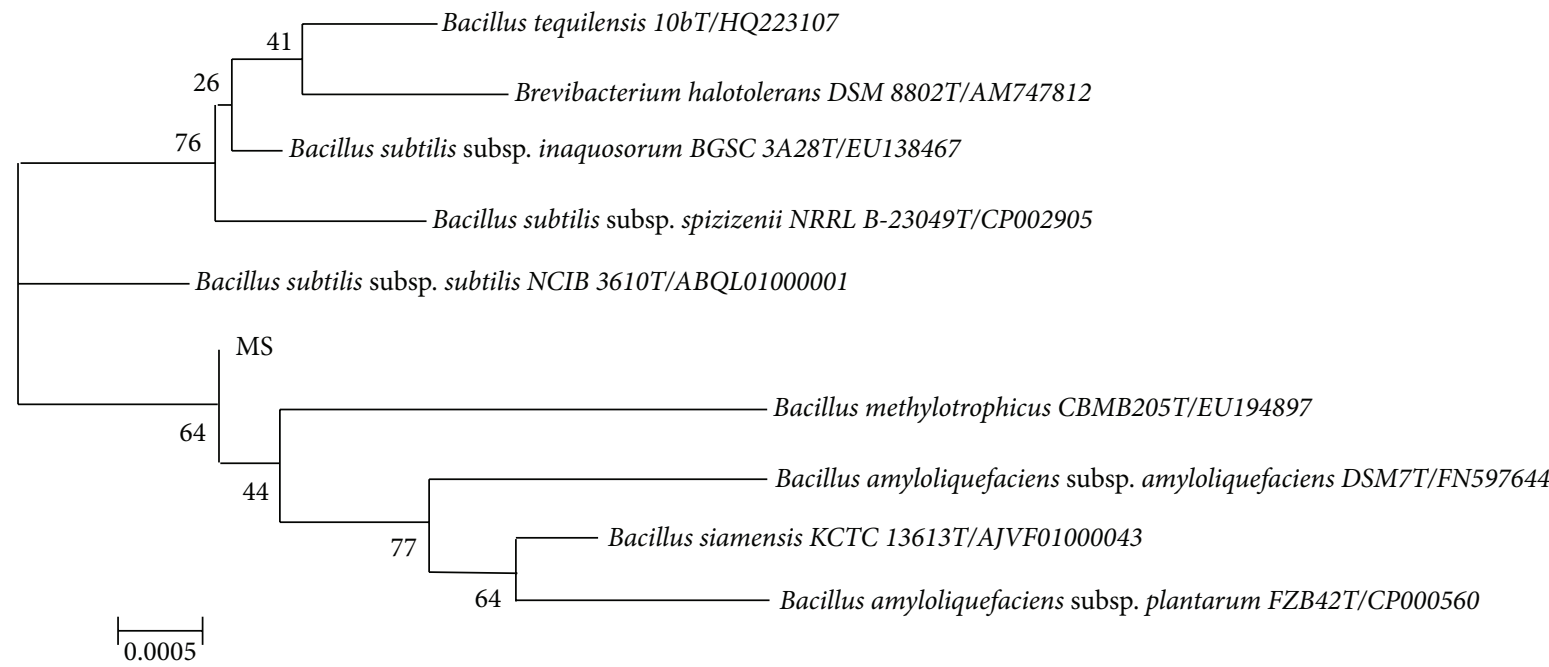

FIGURE 1: The neighbor-joining tree based on the 16S rRNA sequence, demonstrating the phylogenetic position of strain RT10.

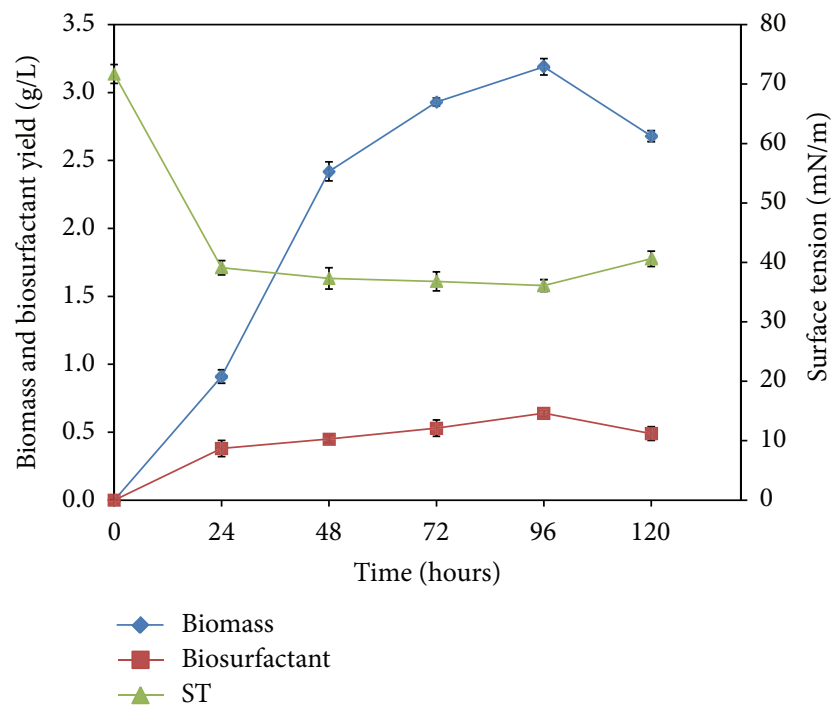

FIGURE 2: Growth, biosurfactant production, and surface tension profiles of Bacillus siamensis grown in MSM with $2 \%(\mathrm{v} / \mathrm{v})$ crude oil at $30^{\circ} \mathrm{C}$ and $150 \mathrm{rpm}$.

3.8. Stability Analysis of the Biosurfactant. The stability of the biosurfactant was checked by subjecting the fermentation broth to conditions of high stress that included temperature, $\mathrm{pH}$, and salinity. When the temperature was varied from $0^{\circ} \mathrm{C}$ to $121^{\circ} \mathrm{C}$, both surface tension and emulsification index $\left(\mathrm{E}_{24}\right)$ showed little variation and remained nearly constant at around $39-40 \mathrm{mN} / \mathrm{m}$ (Figure 4(a)). Similar results were observed by many researchers $[24,25]$.

With respect to $\mathrm{pH}$ variation from 2 to 12 , the values of surface tension were centred around $39 \mathrm{mN} / \mathrm{m}$ without large deviations (Figure 4(b)). The emulsification index $\left(\mathrm{E}_{24}\right)$ dipped to lower values $(60 \%)$, when the $\mathrm{pH}$ was increased. Variability in surface tension and emulsification index was not profoundly observed in various studies involving changes in broth $\mathrm{pH}$ which is in accordance with the literature $[26,27]$.

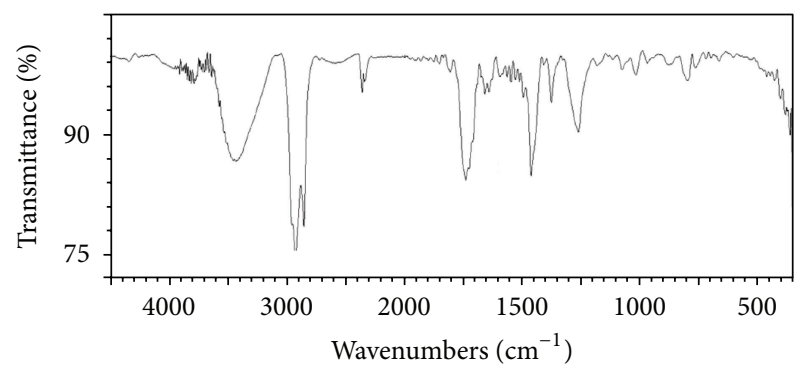

FIGURE 3: Fourier transform infrared spectra (FTIR) of the biosurfactant produced by Bacillus siamensis.

The salinity was varied over the range of $0-20 \%$. The effect on surface tension was similar to the effect of $\mathrm{pH}$ with largely no changes (Figure 4(c)). The emulsification index $\left(\mathrm{E}_{24}\right)$ decreased to $64 \%$ at $20 \%$ saline level. The literature study in the past also confirms that many biosurfactants have stable surface activity even at high levels of salinity [27, 28].

3.9. Suitability for Microbial Enhanced Oil Recovery. The applicability of the biosurfactant was verified using the sand pack column test [21], while maintaining the column at $30^{\circ} \mathrm{C}$, $50^{\circ} \mathrm{C}$, and $70^{\circ} \mathrm{C}$. The oil recovery was $48 \%$ at $30^{\circ} \mathrm{C}$. With rise in temperature, the recovery also increased to $55 \%$ and $60 \%$ at $50^{\circ} \mathrm{C}$ and $70^{\circ} \mathrm{C}$, respectively. Bordoloi and Konwar [29] performed the study at room temperature, $70^{\circ} \mathrm{C}$, and $90^{\circ} \mathrm{C}$ using a sand pack column. They reported oil recovery in the range from $35 \%$ to $60 \%$ across the temperatures, for various Bacillus and Pseudomonas strains.

\section{Conclusions}

In the present study, biosurfactant-producing organisms were enriched and isolated from an oil-contaminated site. The morphological, biochemical, and 16S rRNA analysis were performed to identify the organism. This is the first report 


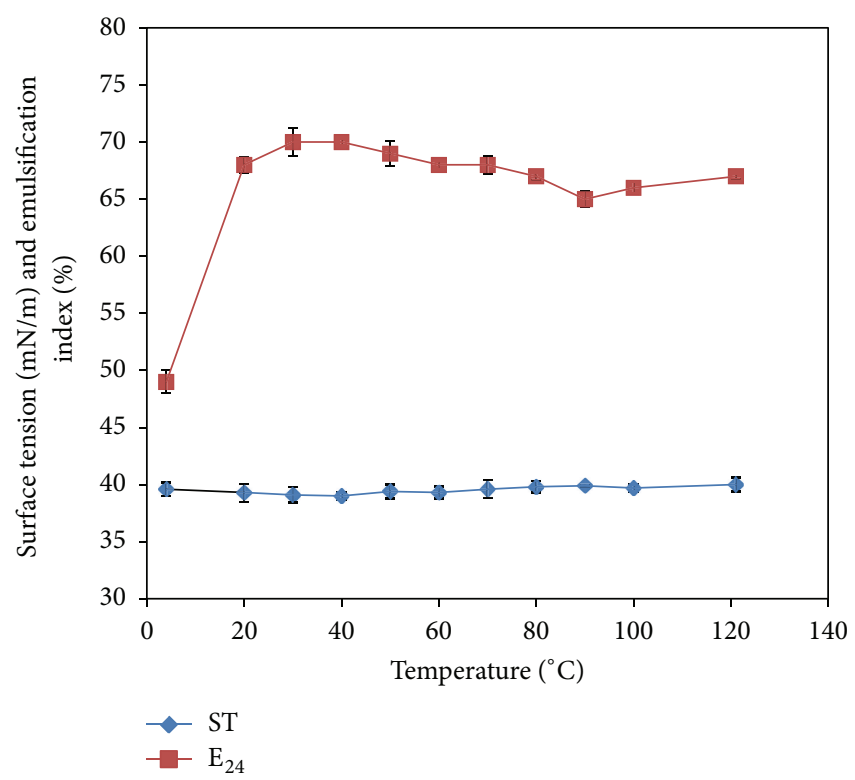

(a)

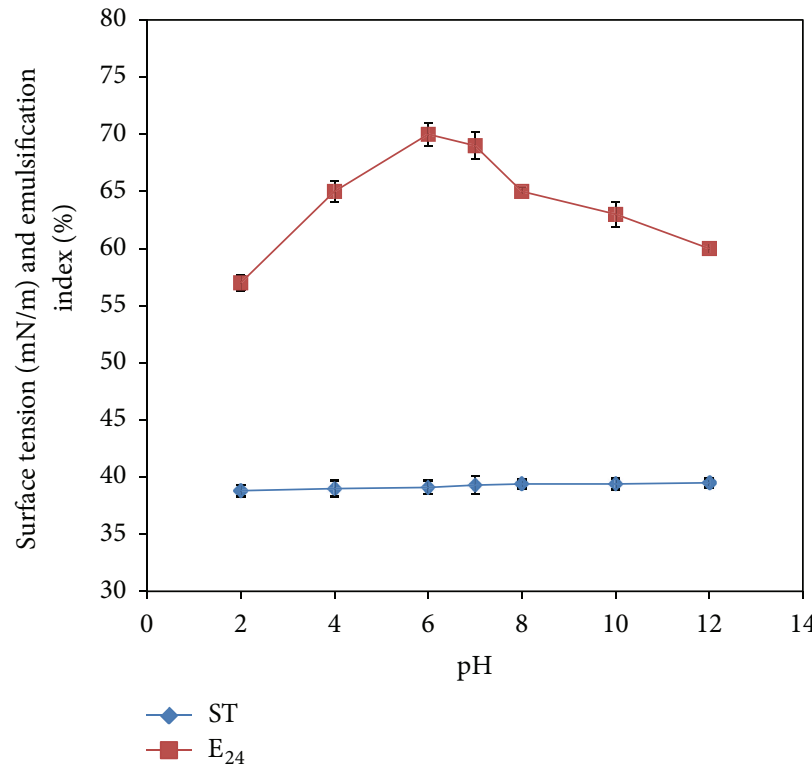

(b)

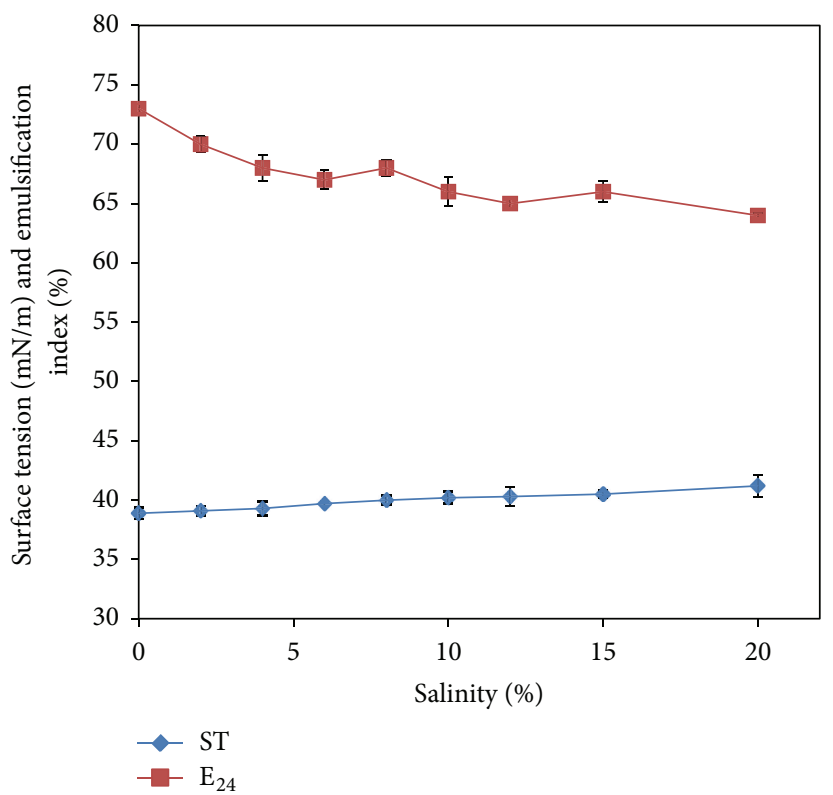

(c)

FIGURE 4: Effect of (a) temperature, (b) $\mathrm{pH}$, and (c) salinity on the stability of biosurfactant.

describing the isolation and use of Bacillus siamensis as a biosurfactant producer. During fermentation studies, the isolate was able to produce a lipopeptide biosurfactant, using crude oil as the sole carbon source. The biosurfactant was extracted and partially characterized by using TLC and FTIR spectroscopy to confirm its chemical nature. A maximum biosurfactant yield of $0.64 \mathrm{~g} / \mathrm{L}$ was obtained at $96 \mathrm{~h}$. The biosurfactant had good surface tension reducing capability, reducing the surface tension to $36.1 \mathrm{mN} / \mathrm{m}$. Stability studies were performed to investigate the effect of extreme variations in temperature, $\mathrm{pH}$, and salinity levels on the surface tension and emulsification capacities of the biosurfactant. In order to examine the suitability of the biosurfactant in enhanced oil recovery processes, sand pack column studies were carried out. To simulate real situations, the column studies were performed at higher temperatures, and the percentage of oil recovery was estimated to be $60 \%$. The organism and its product present a huge potential for use in environmental remediation strategies.

\section{Conflict of Interests}

The authors declare no conflict of interests. 


\section{Acknowledgments}

The authors wish to thank the management of Manipal University for providing necessary laboratory infrastructure to carry out the work. They are also thankful to Dr. B. H. S. Thimmappa and Mr. M. P. Ajithkumar at the Department of Chemistry, Manipal Institute of Technology, for their help with the FTIR analysis.

\section{References}

[1] W. R. Finnerty, "Microbial conversion of hydrocarbons products: commercial perspectives," in Bioconversion of Waste Materials to Industrial Products, A. M. Martin, Ed., Elsevier, Amsterdam, The Netherlands, 1991.

[2] M. G. Healy, C. M. Devine, and R. Murphy, "Microbial production of biosurfactants," Resources, Conservation and Recycling, vol. 18, no. 1-4, pp. 41-57, 1996.

[3] G. Dehghan-Noudeh, M. Housaindokht, and B. S. F. Bazzaz, "Isolation, characterization, and investigation of surface and hemolytic activities of a lipopeptide biosurfactant produced by Bacillus subtilis ATCC 6633," Journal of Microbiology, vol. 43, no. 3, pp. 272-276, 2005.

[4] H. Habe and T. Omori, "Genetics of polycyclic aromatic hydrocarbon metabolism in diverse aerobic bacteria," Bioscience, Biotechnology and Biochemistry, vol. 67, no. 2, pp. 225-243, 2003.

[5] N. Kosaric, "Biosurfactants for soil bioremediation," Food Technology and Biotechnology, vol. 39, no. 4, pp. 295-304, 2001.

[6] L. D. Bushnell and H. F. Haas, "The utilization of certain hydrocarbons by microorganisms," Journal of Bacteriology, vol. 41, pp. 653-673, 1941.

[7] M. Morikawa, Y. Hirata, and T. Imanaka, "A study on the structure-function relationship of lipopeptide biosurfactants," Biochimica et Biophysica Acta, vol. 1488, no. 3, pp. 211-218, 2000.

[8] C. Mulligan, D. Cooper, and R. Neufeld, "Selection of microbes producing biosurfactants in media without hydrocarbons," Journal of Fermentation Technology, vol. 62, no. 4, pp. 311-314, 1984.

[9] L. Rodrigues, A. Moldes, J. Teixeira, and R. Oliveira, "Kinetic study of fermentative biosurfactant production by Lactobacillus strains," Biochemical Engineering Journal, vol. 28, no. 2, pp. 109116, 2006.

[10] D. K. Jain, D. L. Collins-Thompson, H. Lee, and J. T. Trevors, "A drop-collapsing test for screening surfactant-producing microorganisms," Journal of Microbiological Methods, vol. 13, no. 4, pp. 271-279, 1991.

[11] I. Siegmund and F. Wagner, "New method for detecting rhamnolipids excreted by Pseudomonas species during growth on mineral agar," Biotechnology Techniques, vol. 5, no. 4, pp. 265268, 1991.

[12] S. K. Satpute, B. D. Bhawsar, P. K. Dhakephalkar, and B. A. Chopade, "Assessment of different screening methods for selecting biosurfactant producing marine bacteria," Indian Journal of Marine Sciences, vol. 37, no. 3, pp. 243-250, 2008.

[13] A. Persson and G. Molin, "Capacity for biosurfactant production of environmental Pseudomonas and Vibrionaceae growing on carbohydrates," Applied Microbiology and Biotechnology, vol. 26, no. 5, pp. 439-442, 1987.

[14] J. G. Holt, N. R. Krieg, P. H. A. Sneath, J. T. Staley, and S. T. Williams, Bergey's Manual of Determinative Bacteriology, Lippincott, William \& Wilkins, Baltimore, Md, USA, 9th edition, 1994.
[15] H. C. Birnboim and J. Doly, "A rapid alkaline extraction procedure for screening recombinant plasmid DNA," Nucleic Acids Research, vol. 7, no. 6, pp. 1513-1523, 1979.

[16] J. Sambrouk and D. W. Russell, Molecular Cloning: A Laboratory Manual, Cold Spring Harbor Laboratory Press, Cold Spring Harbor, NY, USA, 3rd edition, 2001.

[17] R. S. Makkar and S. S. Cameotra, "Production of biosurfactant at mesophilic and thermophilic conditions by a strain of Bacillus subtilis," Journal of Industrial Microbiology and Biotechnology, vol. 20, no. 1, pp. 48-52, 1998.

[18] D. G. Cooper and B. G. Goldenberg, "Surface-active agents from two Bacillus species," Applied and Environmental Microbiology, vol. 53, no. 2, pp. 224-229, 1987.

[19] A. W. Adamson, Physical Chemistry of Surfaces, Wiley Interscience, New York, NY, USA, 5th edition, 1990.

[20] P. Das, S. Mukherjee, and R. Sen, "Antimicrobial potential of a lipopeptide biosurfactant derived from a marine Bacillus circulans," Journal of Applied Microbiology, vol. 104, no. 6, pp. 1675-1684, 2008.

[21] A. S. Abu-Ruwaida, I. M. Banat, S. Haditirto, A. Salem, and M. Kadri, "Isolation of biosurfactant-producing bacteria product characterization, and evaluation," Acta Biotechnologica, vol. 11, no. 4, pp. 315-324, 1991.

[22] P. G. Carrillo, C. Mardaraz, S. I. Pitta-Alvarez, and A. M. Giulietti, "Isolation and selection of biosurfactant-producing bacteria," World Journal of Microbiology and Biotechnology, vol. 12, no. 1, pp. 82-84, 1996.

[23] R. S. Makkar and S. S. Cameotra, "Biosurfactant production by a thermophilic Bacillus subtilis strain," Journal of Industrial Microbiology and Biotechnology, vol. 18, no. 1, pp. 37-42, 1997.

[24] A. Khopade, R. Biao, X. Liu, K. Mahadik, L. Zhang, and C. Kokare, "Production and stability studies of the biosurfactant isolated from marine Nocardiopsis sp. B4," Desalination, vol. 285, pp. 198-204, 2012.

[25] A. Aparna, G. Srinikethan, and H. Smitha, "Production and characterization of biosurfactant produced by a novel Pseudomonas sp. 2B," Colloids and Surfaces B, vol. 95, pp. 23-29, 2012.

[26] L. A. Sarubbo, J. M. De Luna, and G. M. De Campos-Takaki, "Production and stability studies of the bioemulsifier obtained from a new strain of Candida glabrata UCP 1002," Electronic Journal of Biotechnology, vol. 9, no. 4, pp. 400-406, 2006.

[27] J. Wang, G. Ji, J. Tian, H. Zhang, H. Dong, and L. Yu, "Functional characteriz ation of a biosurfactant-producing thermo-tolerant bacteria isolated from an oil reservoir," Petroleum Science, vol. 8, no. 3, pp. 353-356, 2011.

[28] S. N. Al-Bahry, Y. M. Al-Wahaibi, A. E. Elshafie et al., "Biosurfactant production by Bacillus subtilis B20 using date molasses and its possible application in enhanced oil recovery," International Biodeterioration Biodegradation, vol. 81, pp. 141146, 2012.

[29] N. K. Bordoloi and B. K. Konwar, "Microbial surfactantenhanced mineral oil recovery under laboratory conditions," Colloids and Surfaces B, vol. 63, no. 1, pp. 73-82, 2008. 

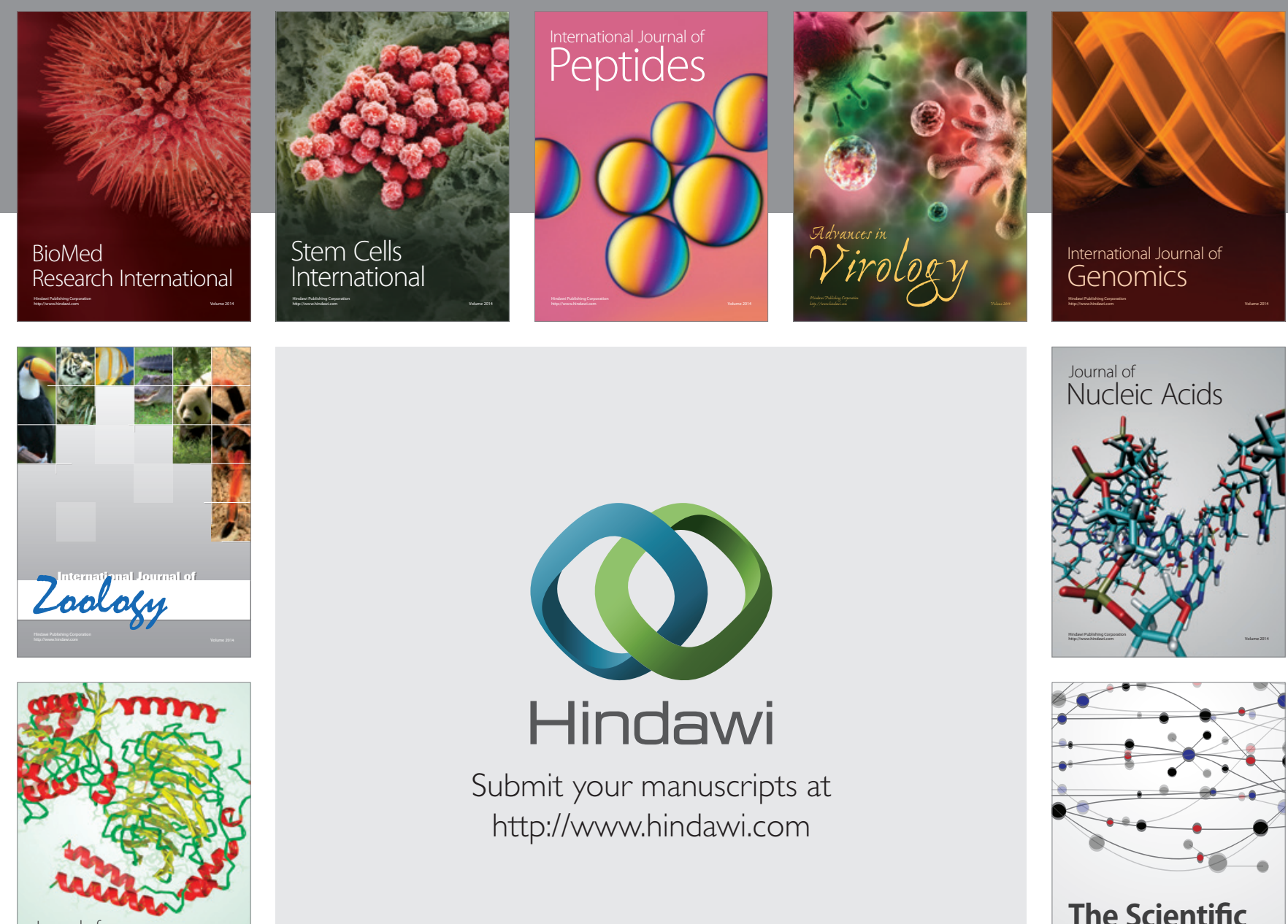

Submit your manuscripts at

http://www.hindawi.com

Journal of
Signal Transduction
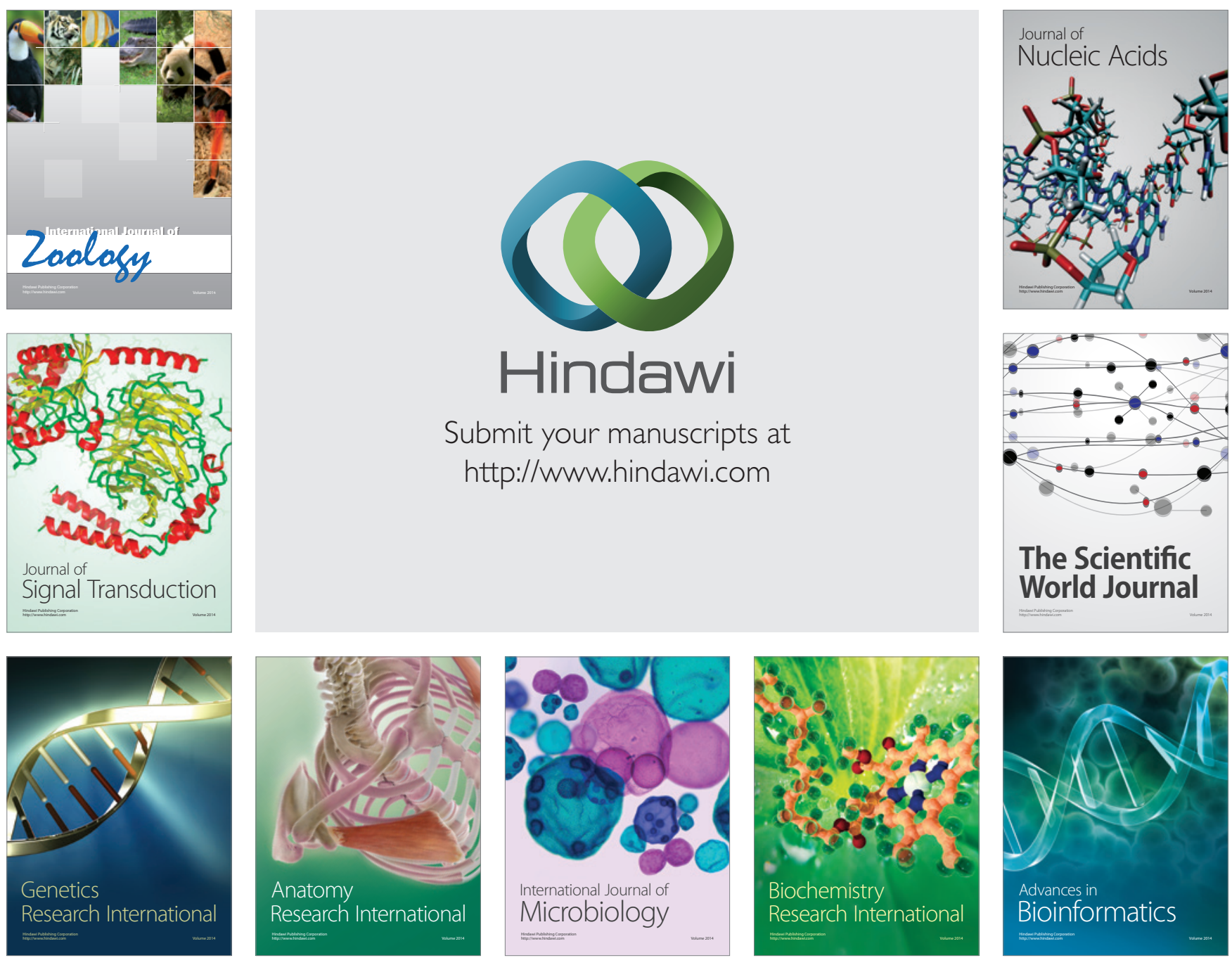

The Scientific World Journal
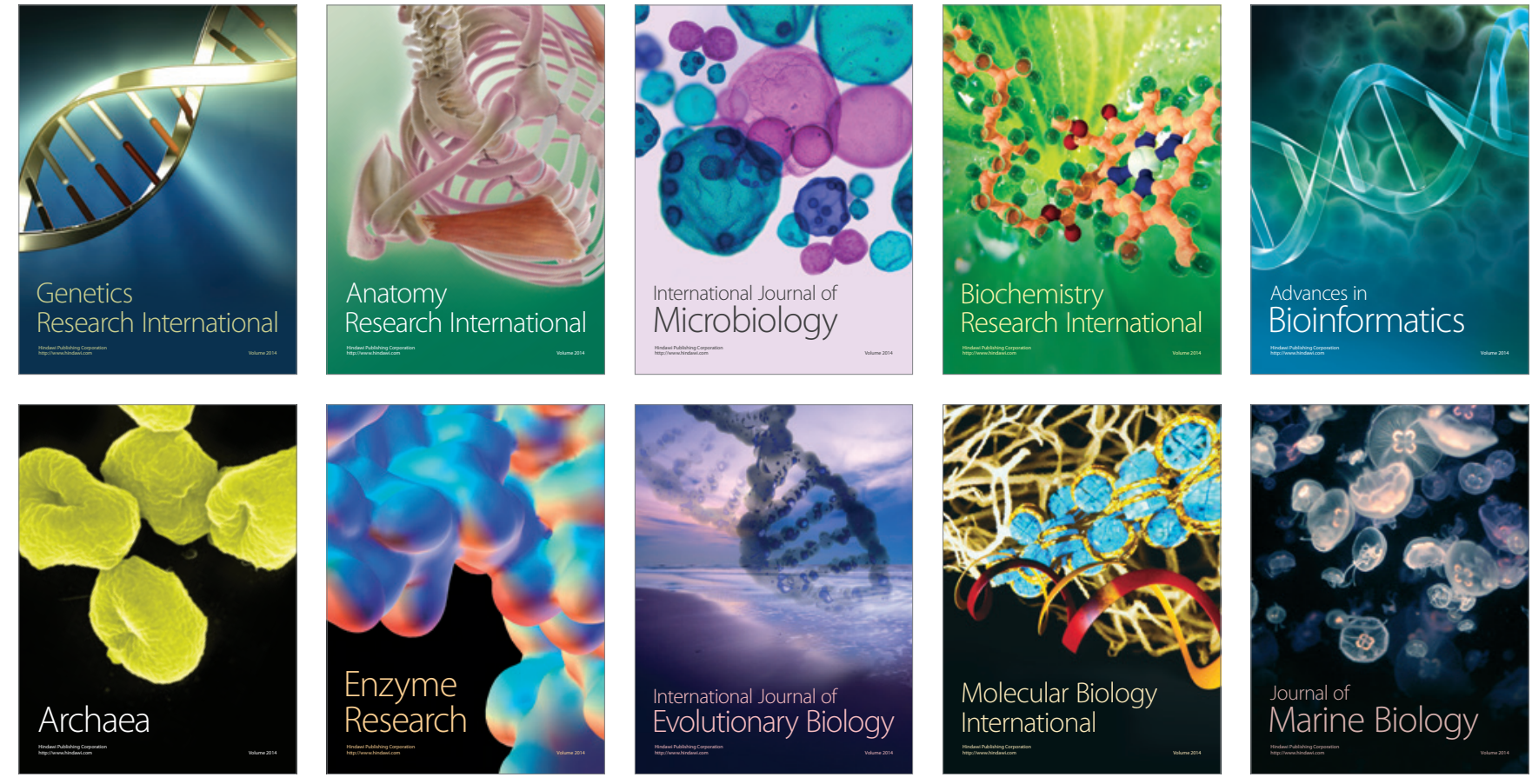